\title{
Changing trends of breast cancer awareness in young females of north India: A pilot study from a rural cancer hospital
}

\section{Vivek Tiwari, Piyush Shukla', Gourav Gupta²}

Departments of Radiation Oncology, Artemis Healthcare Institute, Gurgaon, Haryana, ${ }^{1}$ Apollo Bhilai Scan and Research Hospitals, Bhilai Chhattisgarh, ${ }^{2}$ Rajiv Gandhi Cancer Institute and

Research Centre, Delhi, India

Address for the Correspondence: Dr. Vivek Tiwari,

B-79, Rajved colony, Nayapura, Kolar Road, Bhopal - 462 042, Madhya Pradesh, India. E-mail: dr_vivektiwari@ rediffmail.com

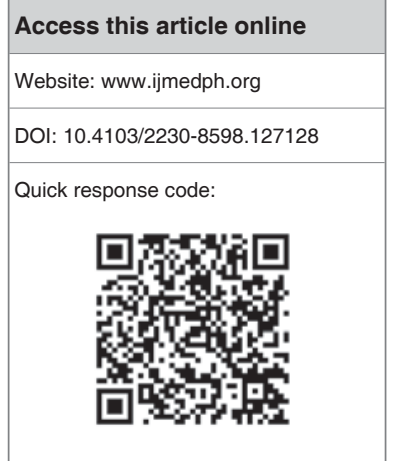

\begin{abstract}
Aim: To assess the spectrum of presentation of young (18-35 years) females to a rural cancer hospital and to correlate it with the level of education. Materials and Methods: Ninety cases of the selected age group were prospectively studied for the manner of presentation and level of education. Results: Majority patients $(57.77 \%)$ presented with breast related symptoms. $81.1 \%$ of the patients were educated at least up to secondary school education. Conclusions: Owing to the improved education levels and awareness, the young rural females are more informed about breast related symptoms and are seeking proper care for the same. A robust rural cancer registry system may document this changing scenario that may well contrast with the traditional beliefs and learning of cancer epidemiology.
\end{abstract}

Key words: Breast cancer, education, India, rural

\section{INTRODUCTION}

The lack of skilled service providers in rural areas of India has emerged as the most important constrain in achieving universal healthcare. India has about 1.4 million medical practitioners, $74 \%$ of whom live in urban areas where they serve only $28 \%$ of the population, while the rural population remains largely underserved. ${ }^{[1]}$ Breast cancer $(\mathrm{BC})$ is the leading cause of cancer in women in the western world and is emerging as the leading cancer in women in India as well. ${ }^{[2]}$ The only rural cancer registry in India (Barshi) has indicated decreasing trends of cancer of cervix and increasing trends of $\mathrm{BC}$ in the rural regions of India. ${ }^{[3]}$ In all but one (Barshi) rural regions of India, there are no means of a proper cancer registry system and the system of assessing the cancer burden is not regularized.

$\mathrm{BC}$ awareness programs are more concentrated in the cities and have not reached to all the remote and rural parts of the country. Women often do not present for medical care early enough due to various reasons such as illiteracy, lack of awareness, and financial constraints and majority of females present in advanced stages. ${ }^{[4]}$

However, off late there has been an overhaul of the scenario in the rural regions that has made the rural population more educated, informed, and aware of the current health trends. Proper education is an imperative tool in the battle against cancer. Men and women with no education have higher overall cancer incidence rates compared to the educated population. A high incidence of $\mathrm{BC}$ has been observed with increasing educational levels. ${ }^{[5]}$

This study was conducted in a rural cancer hospital of north India over a period of 15 months to assess the current scenario of BC awareness, symptomatology, and education levels in the young females presenting to the hospital that caters to the neighboring rural population.

\section{MATERIALS AND METHODS}

All the young females (18-35 years) presenting to the hospital with breast related symptoms were prospectively studied over a period of 15 months from August 2011 to November 2012. Patients 
were evaluated for their symptoms, regarding the level of basic education, and at the same time advised needful diagnostic tests and treatment.

\section{RESULTS}

A total of 90 young females were seen in the study duration. Of these, 49 (54.44\%) belonged to the 18-25 years age group, 22 (24.44\%) were in the 26-30 years group, while 19 (21.11\%) belonged to the 31-35 years group [Figure 1].

Of the 90 cases, $43(47.77 \%)$ had completed formal school education, $30(33.33 \%)$ had either completed or were perusing some form of college education, while 17 (18.88\%) were either totally educated or had received primary education only [Figure 2].

Breast related symptoms $(n=52)$ constituted the majority $(57.77 \%)$ of cases presenting for evaluation, followed by gynecologic symptoms $(n=23,25.55 \%)$ [Figure 3].

The overall distribution of breast related symptoms encompassed that of a breast lump in 26 cases (50\%), axillary lump in three cases $(5.76 \%)$, nipple discharge in five cases $(9.61 \%)$, nonspecific complains including tightness/pain in breast or seeking a clinician checkup in seven cases $(13.46 \%)$. Eleven cases $(21.15 \%)$ were those

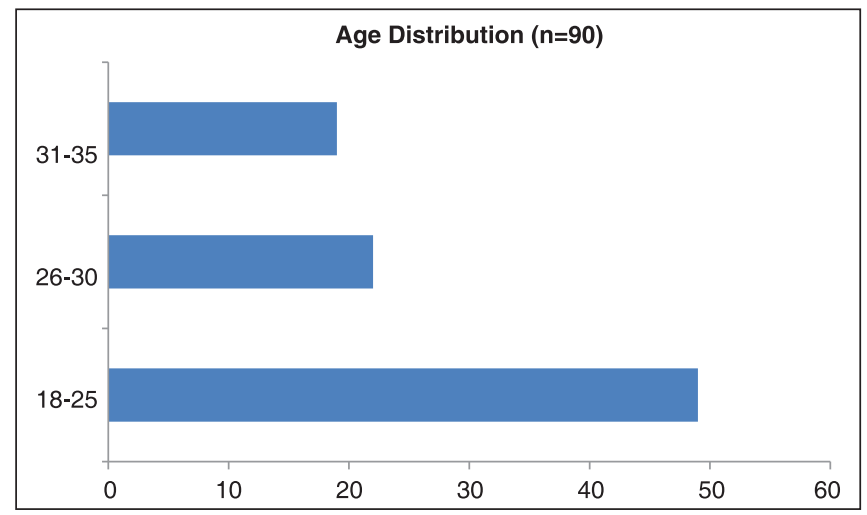

Figure 1: Age distribution of the cases

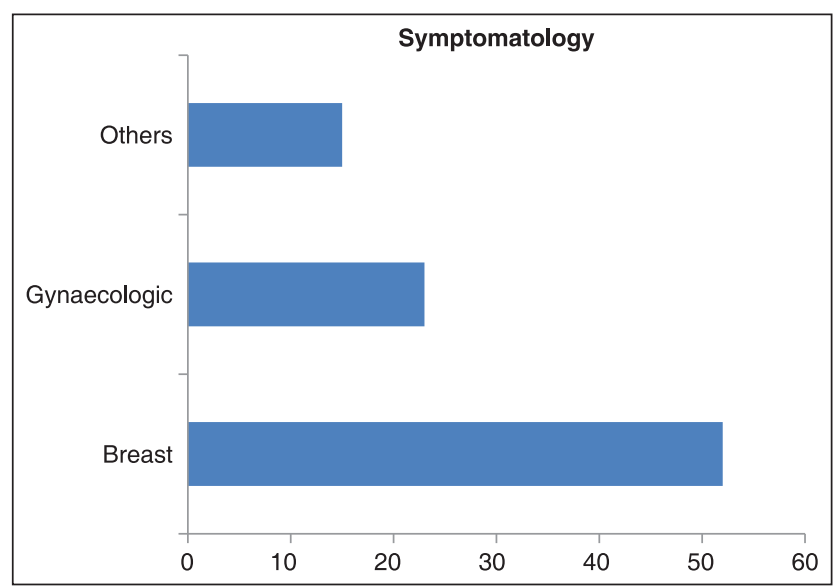

Figure 3: Presenting symptoms of a histopathological proven malignancy and presented for needful management [Figure 4].

Of the 52 cases presenting with breast related symptoms, 36 cases (69.23\%) had completed formal schooling education, of which 16 (44.44\%) had completed or were perusing college education and 16 cases $(30.76 \%)$ had a lower/no education level [Figure 5].

After detailed history taking, clinical examination and needful diagnostic evaluation, four of the 52 cases $(7.69 \%)$ were diagnosed to be positive for BC. Of these, three had presented with a clinically palpable lump, while one patient had the symptom of nipple discharge.

\section{DISCUSSION}

Cancer is a global problem that accounts for almost $13 \%$ of deaths worldwide. Sixty percent of which will be in developing countries. It is potentially the most preventable disease and with current resources, one-third of tumors could be preventable, and another one-third of newly diagnosed cancer patients could experience increased survival or early-stage detection. ${ }^{[6]}$

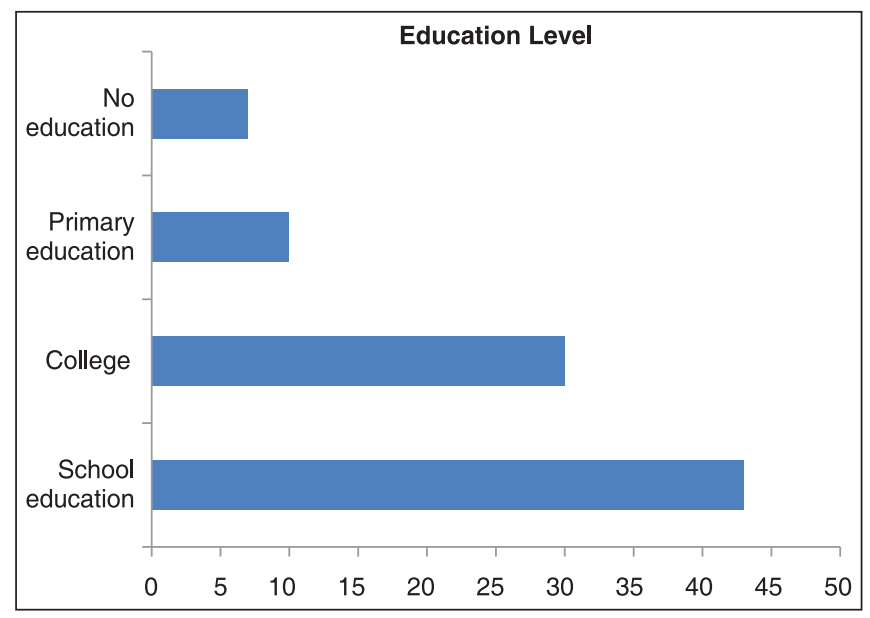

Figure 2: Overall education level

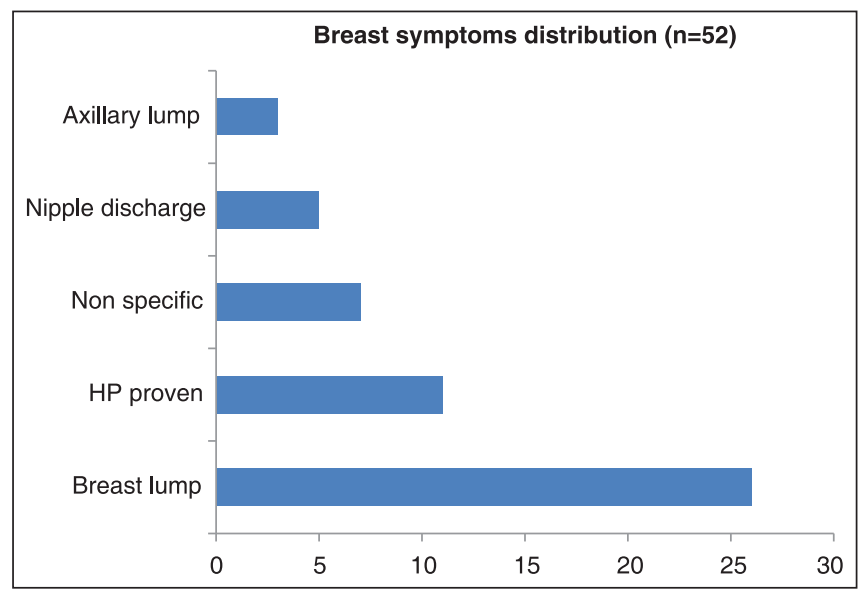

Figure 4: Distribution of breast related symptoms 


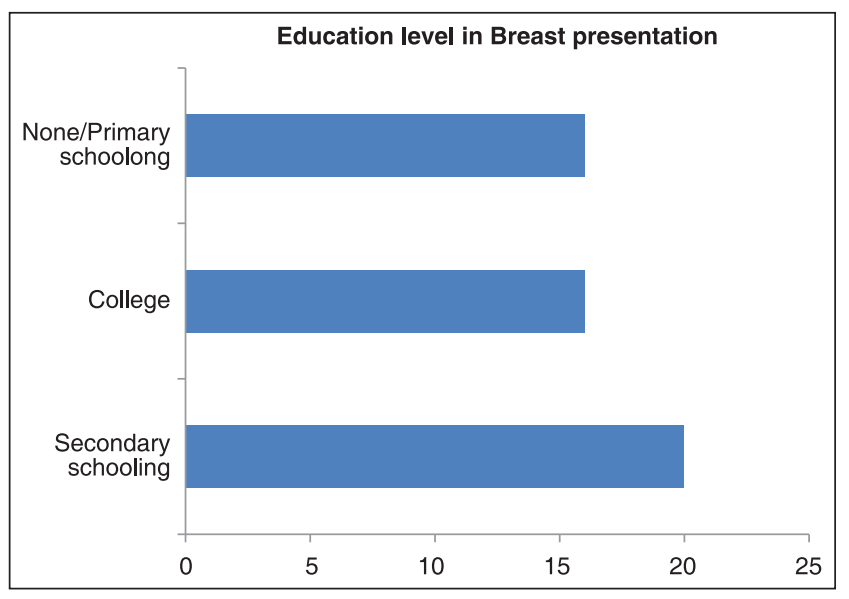

Figure 5: Education level in patients with breast symptoms

$\mathrm{BC}$ among Indian women accounts for the second most common cause of cancer. Although the incidence in urban areas are increasing, the rural India is notorious in presenting at an advanced stage that accounts for $50-70 \%$ of the cases. ${ }^{[7]}$ Lack of awareness regarding the disease coupled with no affordability or nonavailability of facilities for early detection and treatment are some of the major determinants of this. ${ }^{[8]}$

Studies have revealed that in developing countries, advanced breast disease is common in younger patients belonging to underprivileged and remote rural areas and great efforts are required to educate people so as to make early diagnosis possible. ${ }^{[9]}$ With more and more women in rural India becoming educated, one could foresee $\mathrm{BC}$ becoming more frequent even in rural areas of India in future. ${ }^{[5]}$

There has been a major breakthrough in achieving a scenario where the government has made a huge contribution by spreading awareness in the rural and remote areas that deserves mention. In the present scenario, a number of programs are being conducted on the national basis under National Rural Health Mission that have helped the cause of early detection by organizing training and education for the health workers regarding clinical breast examination. Proper screening at the root level has definitely improved the scenario of presentation as is evident from this study. The availability of treatment options at the district level have been instrumental as the economically poor people are not required to go for treatment to a far off place which has been the major cause for late presentation till now. ${ }^{[7]}$ The Indian government has been instrumental in creating programs like the National Cancer Control Program, and along with nongovernment agencies has been constantly trying to educate the rural population with initiatives like regular health checkups, awareness cum screening camps, popularizing the practice of breast self-examination and examination by trained personnel ${ }^{[7]}$ that appears to have started paying returns.

In addition, over the past years, there has been a sustained effort to also improve the level of basic education in the rural regions of India. In the region where the study was conducted, a fully- fledged university was functional and the people were keen to be formally educated. Also the level of primary and secondary school education was contributory towards the encouraging results of the study.

In our study, 73 out of the 90 young females were educated at least up to secondary school and were aware of the basic signs and symptoms of BC in particular. Although only a few patients knew the methodology of breast self-examination, they were keen to learn, and demonstrated satisfactory compliance on follow-up.

Another important observation of our study is the emerging need of a proper cancer registry system that caters to the data of the rural regions of India. At present, the population covered by cancer registry covers only $5 \% \cdot{ }^{[10]}$ There is an utmost need to establish a rural cancer registry system that is able to collect data and analyze it, thereby predicting the actual scenario and changing trends in the rural India. We also suggest that many such rural cancer hospitals should come forward and form a pooled database for better understanding of cancer scenario in the rural India based on which effective preventive and curative approach can be tailored.

\section{CONCLUSION}

Cervical cancer is still considered to be a major killer among developing countries, especially in rural settings. ${ }^{[11]}$ However, in our study, we observed a higher incidence of presentation of breast related symptoms in the cohort studied. Although the number of frank malignant cases diagnosed were less, but the presentation points towards the level of increased awareness among the young rural females regarding the symptoms of BC.

This study comes as an initiative that projects the changing trends of $\mathrm{BC}$ in the rural north India. Improved education levels, along with the sustained efforts to create awareness regarding $\mathrm{BC}$ has started to pay dividends with respect to the early presentation and an overall improved outlook of the young females towards this highly preventable and dreaded disease. We also emphasize need of a proper rural cancer registry system to cater to the needs of rural population of India.

\section{ACKNOWLEDGEMENT}

Mirpur Institute of Medical Sciences, Mirpur, Rewari, Haryana.

\section{REFERENCES}

1. Sundararaman T, Gupta G. Indian approaches to retaining skilled health workers in rural areas. Bull World Health Organ 2011;89:73-7.

2. Reddy N, Ninan T, Tabar L, Bevers T. The results of a breast cancer screening camp at a district level in rural India. Asian Pac J Cancer Prev 2012;13:6067-72.

3. Yeole BB. Trends in cancer incidence in female breast, cervix uteri, corpus uteri, and ovary in India. Asian Pac J Cancer Prev 2008;9:119-22.

4. Agarwal G, Ramakant P. Breast cancer care in India: The current scenario and the challenges for the future. Breast Care (Basel) 2008;3:21-7.

5. Swaminathan R, Selvakumaran R, Vinodha J, Ferlay J, Sauvaget C, Esmy PO, et al. Education and cancer incidence in a rural population in south India. Cancer Epidemiol 2009;33:89-93. 
6. López-Gómez M, Malmierca E, de Górgolas M, Casado E. Cancer in developing countries: the next most preventable pandemic. The global problem of cancer. Crit Rev OncolHematol 2013;88:117-22.

7. Das S, Patro KC. Cancer care in the rural areas of India: A firsthand experience of a clinical oncologist and review of literatures. J Cancer Res Ther 2010;6:299-303.

8. Rao RS, Nair S, Nair NS, Kamath VG. Acceptability and effectiveness of a breast health awareness programme for rural women in India. Indian J Med Sci 2005;59:398-402.

9. Malik AM, Pathan R, Shaikh NA, Qureshi JN, Talpur KA. Pattern of presentation and management of ca breast in developing countries. There is a lot to do. J Pak Med Assoc 2010;60:718-21.

10. Mathew A. Cancer registration with emphasis on Indian Scenario. In:
Basic Information for Cancer Registry Documentation. Mathew A, editor. Trivandrum: Regional Cancer Centre; 2003. p. 11-7.

11. Singh E, Seth S, Rani V, Srivastava DK. Awareness of cervical cancer screening among nursing staff in a tertiary institution of rural India. J Gynecol Oncol 2012;23:141-6.

How to cite this article: Tiwari V, Shukla P, Gupta G. Changing trends of breast cancer awareness in young females of north India: A pilot study from a rural cancer hospital. Int J Med Public Health 2014;4:62-5.

Source of Support: Nil, Conflict of Interest: None declared. 